\title{
Photosensitization Studies in Selected Dyestuffs
}

\author{
VIKESH KUMAR, M.R.TRIPATHI*, \\ MANISH KUMAR and GOPAL SHUKLA \\ Department of Chemistry, \\ D.A.V.P.G. College, Kanpur 208001 Uttar Pradesh, India. \\ tripathimadhoram@yahoo.co.in
}

Received 20 November 2008; Accepted 1 January 2009

\begin{abstract}
There are various dyestuffs species to produce reactive oxygen such as singlet oxygen $\mathrm{O}_{2}$ and super oxide radicals. Irradiation with sun light in vitro, the dyestuff like benzanthrone, metanil yellow and $p$ aminodiphenylamine were found to produce reactive oxygen species such as singlet oxygen $\left({ }^{1} \mathrm{O}_{2}\right)$ and/or superoxide radicals $\left(\mathrm{O}_{2}^{-}\right)$. However benzanthrone produces detectable amount of ${ }^{1} \mathrm{O}_{2}$ Although metanil yellow and $p$-aminodiphenylamine ( $p$-ADPA) did not produce detectable amounts of ${ }^{1} \mathrm{O}_{2}$ under similar conditions. The above dyestuffs are routinely used in textiles, cosmetics, detergents, leather industries as well as food additives. In view of the fact that workers exposed to some of these chemicals during manufacture, pulverization and storage develop edema and even skin cancers in the exposed areas of skin. We believe that activated oxygen species may play a major role in the development of these symptoms.
\end{abstract}

Keywords: Dyes, Benzanthrone, Photosensitization, Singlet oxygen, Superoxide radicals.

\section{Introduction}

Production of synthetic dyes in India is about 25000 metric tons every year ${ }^{1}$. Which are Industrial health hazards to people ${ }^{2}$. Dyestuff industries have occupied a prominent place in the industrial organization of the modern world. One of the major routes to incorporate dyestuffs in our biological system is by absorption through skin. Some dyes have different degrees of binding ability with protein, collagen and lipids ${ }^{3-4}$. Study shows that toxic effect of these synthetic dyes are observed in the presence of the ultraviolet component of sunlight $(285-400 \mathrm{~nm})^{5}$. Photosensitization reactions in our analysis is oxygen dependent in which a photo excited dye transfers energy to molecular oxygen to produce activated oxygen species like singlet oxygen $\left({ }^{1} \mathrm{O}_{2}\right)$, super oxide radical $\left(\mathrm{HO}_{2}\right.$ or $\left(\mathrm{O}_{2}{ }^{-}\right)$, hydroxyl radical $(\mathrm{OH})$ and hydrogen peroxide. The activated oxygen species contribute to oxidative degradation of protein, enzymes, lipids and other target 
molecules of cellular systems ${ }^{6-8}$ and are also responsible to act as tumor promoters in the development of cancer".

In present study the reason for taking benzanthrone ( $7 H$-benz(de)anthrance-7-one) is used in the synthesis of many vat and disperse dyes. It has been observed that workers coming into contact with it during manufacture, pulverization and storage develop itching, burning sensation, erythema, roughness, dryness and pigmentation of the $\operatorname{skin}^{10-11}$. Orange II [monoazo, C.I. acid yellow, orange 7 (15510)], a sodium or calcium salt of $p$-(2-hydroxyl-1-naphthalenyl) azo benzenesulfonic acid is used in dyeing of paper, soaps $e t c^{12}$. A blend of orange II with metanil yellow under the trade name to cause deleterious effects in our biological system ${ }^{13}$. Metanil yellow [monoazo, C.I. acid yellow 36 (13065)], a sodium or calcium salt of $m$-( $p$-anilinophenyl-azo) benzenesulfonic acid, is used in the coloring of foodstuffs, soaps, shoe polishes, wood stains, paper staining and cosmetics. $p$-Aminodiphenylamine ( $p$-ADPA) and metanilic acid are important metabolites of metanil yellow ${ }^{14}$ and are considered to be an active ingredient of metanil yellow induced toxicity ${ }^{15}$. $p$-ADPA is used as an intermediate for the synthesis of photographic chemicals, and the manufacture of dyeing reagents ${ }^{16-17}$. It is also used as an ingredient in oxidizing types of hair dyes ${ }^{18}$. Its properties of skin irritation and sensitization are well known ${ }^{19}$.

\section{Experimental}

Benzathrone was obtained from Kalyan Dye Stuff Industry, Kalyan, Bombay. Metanil yellow and orange II were obtained from M/s Vsco Products Pvt. Ltd., Metanilic acid and nitro blue tetrazolium (NBT) were procured from Sisco Research Lab, Bomaby. 1,4-Diazabicyclo- (2,2,2)-octoane (DABCO), $p$-ADPA, superoxide dismutase (SOD) and $N$, $N$-demethyl- $p$-nitrosoaniline (RNO) were obtained from Sigma Chemical Co., U.S.A. Sodium azide and histidine (HIS) were obtained form HiMedia Lab., Bombay. Other chemicals and solvents used throughout the study were of analytical grade and obtained form E. Merck- BDH Chemical Company. The dyes were further purified by column chromatography.

Ultraviolet and visible spectra were recorded on a Shumatzu 450 UV/visible spectrophotometer using quartz cells of $5 \mathrm{~cm}$ path length. Irradiation experiments were done as follow: $10-\mathrm{mL}$ solutions were taken in a Petri dish $(6 \mathrm{~cm}$ diameter $)$ and irradiated with direct sunlight. The temperature was maintained at $20 \pm 2{ }^{0} \mathrm{C}$ by using a constant temperature water bath. Irradiation experiments were done in Kanpur, U.P. on sunny days preferably between 9:00 and $11.00 \mathrm{am}$. The irradiance of emitted light was measured by an International Light IL-730 UV Actinic Radiometer (International Light Company, Newburyport, Mass., U.S.A.) equipped with a calibrated and cosinecorrected ultraviolet radiation detecting probe. Sunlight produced an average ultraviolet radiaton of approx. $1.2 \pm 0.1 \times 102 \mathrm{erg} . \mathrm{mm}^{-2} . \mathrm{s}^{-1}$ in the UV-A range (320-400 $\mathrm{nm})$. It also produced approx. $1.0 \pm 0.1 \times 10^{-4} \mathrm{erg} . \mathrm{mm}^{-2} \cdot \mathrm{s}^{-1}$ of UV-B $(285-320 \mathrm{~nm})$ radiations under similar conditions. The results of intensity measurement were also confirmed by chemical actinometry ${ }^{20}$. Formation of ${ }^{1} \mathrm{O}_{2}$ was determined in aqueous solutions by the method of Kraljic and Mohsini ${ }^{21}$. With water insoluble chemicals, reactions were done in dimethyl formamide (DMF) solution (5-20\% in $0.01 \mathrm{M}$ phosphate buffer, $\mathrm{pH} 7$ ). A $10 \mathrm{~mL}$ solution of RNO was prepared in a phosphate buffer $(0.01 \mathrm{M}, \mathrm{pH} 7)$ and optical density was adjusted between 1.2 and 1.4 . Histidine $\left(1 \times 10^{-2} \mathrm{M}\right)$ was added to the RNO solution as a selective acceptor of ${ }^{1} \mathrm{O}_{2}$. Stock solutions $(1 \mathrm{mg} / \mathrm{mL})$ 
of test compounds were prepared in ethanol, DMF or dimethyl sulfoxide (DMSO). RNO and HIS samples were irradiated with various concentrations of test compounds $(0.1,1.0$ and $10 \mu \mathrm{g} / \mathrm{mL})$ and sunlight dose (0-40 $\mathrm{min})$. Singlet oxygen forms a transannular peroxide intermediate with HIS leading to the bleaching of ${ }^{1} \mathrm{O}_{2}$ was also established by examining the reaction kinetics in $\mathrm{D}_{2} \mathrm{O}$ and by carrying out quenching studies with sodium azide ${ }^{22}$ and $\mathrm{DABCO}^{23}$. Solvents like $\mathrm{D}_{2} \mathrm{O}$ and $\mathrm{C}_{2} \mathrm{H}_{5} \mathrm{OH}$ are known to prolong the life time of singlet oxygen ${ }^{24}$. Formation of $\left(\mathrm{O}_{2}^{-}\right)$was studied by monitoring the photosensitized reduction of $\mathrm{NBT}^{25}$ with some modifications. Reduction of NBT by $\left(\mathrm{O}_{2}{ }^{-}\right)$leads to the formation of a blue coloured product (nitro blue formazan), which is quantitatively estimated spectrophotometrically at $560 \mathrm{~nm}$. A $1.67 \times 10^{-4} \mathrm{M}$ solution of NBT was prepared in carbonate buffer $(0.01 \mathrm{M}, \mathrm{pH} 10)$ containing $10-20 \%$ DMF to keep the reaction product in solution. $10 \mathrm{~mL}$ solutions were irradiated with various concentrations of test samples in sunlight for varying lengths of time. Further evidences for the generation of $\left(\mathrm{O}_{2}{ }^{-}\right)$were obtained by performing quenching studies with $\mathrm{SOD}^{26}$.

\section{Results and Discussion}

\section{Singlet oxygen production}

A comparative study of the ${ }^{1} \mathrm{O}_{2}$ producing ability of various dyes is summarized in Table 1. Only benzathrone was found to generate sufficient ${ }^{1} \mathrm{O}_{2}$ to be monitored spectrophotometrically by a drop in optical density at $440 \mathrm{~nm}$ due to bleaching of RNO by the transannular peroxide intermediate of HIS and ${ }^{1} \mathrm{O}_{2}$. The ${ }^{1} \mathrm{O}_{2}$ generating potential of benzathrone was comparable to well known photosensitizing agents like anthracene.

\section{Dose-response relation}

The formation of ${ }^{1} \mathrm{O}_{2}$ from benzathrone was found to be both concentration and sunlight dose-dependent. A nearly linear relationship was found between the concentration of benzathrone $(1-10 \mu \mathrm{g} / \mathrm{mL})$ and the amount of ${ }^{1} \mathrm{O}_{2}$ produced after $15 \mathrm{~min}$ exposure with sunlight (Figure 1). The study was done using a $10 \mu \mathrm{g} / \mathrm{mL}$ concentration of benzanthrone. The relationship between ${ }^{1} \mathrm{O}_{2}$ production and concentration of test compound was observed in dilute solutions only. At higher concentration the linearity was disturbed due to low solubility of benbzanthrone as well as low penetration of solar radiation into the colloidal irradiation solution.

\section{Super oxide radical's production}

It was interesting to know that metanil yellow and $p$-aminodiphenylamine, the two dyes which gave a negative test for ${ }^{1} \mathrm{O}_{2}$, were found to produce $\left(\mathrm{O}_{2}^{-}\right)$in appreciable yields (Table 1 \& Figure 3). Benzanthrone produced $\left(\mathrm{O}_{2}^{-}\right)$in almost the same quantity as produced by anthracene and hematoporphyrin ${ }^{27} . p$-Aminodiphenylamine produced $\left(\mathrm{O}_{2}^{-}\right)$comparable to benzanthrone, whereas metanil yellow produced lower amounts of $\left.\mathrm{O}_{2}^{-}\right)$in comparison to its metabolite. Metanilic acid, orange II and sulfanilic acid did not produce detectable amounts of $\left(\mathrm{O}_{2}^{-}\right)$under similar conditions.

Selected dyes and dyestuffs, benzanthrone, orange II, metanil yellow and $p$-ADPA most commonly used in colouring and textile industries as well as food additives were examined for their ability to produce activated oxygen species $\left[{ }^{1} \mathrm{O}_{2}\right.$ and $\left.\left(\mathrm{O}_{2}{ }^{-}\right)\right]$under normal sunlight with a view to investigating the possible occupational health hazard to people through a series of photodynamic oxidation reactions leading to cell damage. 


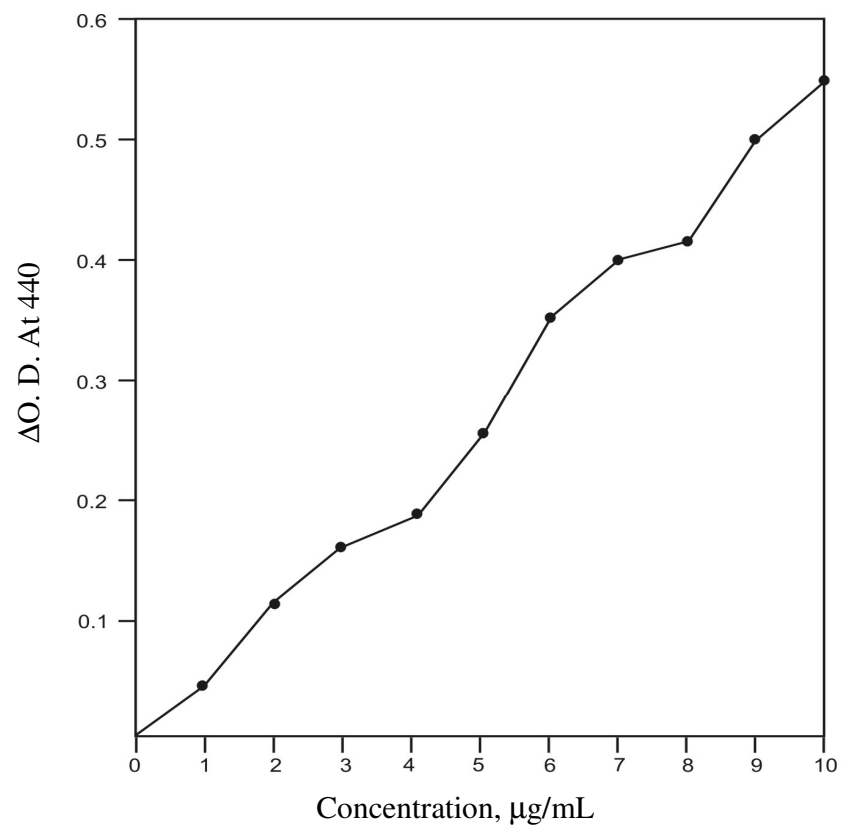

Figure 1. Production of singlet oxygen by benzathrone $1-10 \mu \mathrm{g} / \mathrm{mL}$ upon sunlight $15 \mathrm{~min}$ as measured by recording a decrease in UV-absorption of $\mathrm{RNO}\left(32 \pm 0.2 \times 10^{-5} \mathrm{M}\right.$ in $0.01 \mathrm{M}$ phosphate buffer with $20 \%$ DMF, pH 7) containing HIS $\left(1 \times 10^{-2} \mathrm{M}\right)$ as a selective acceptor of ${ }^{1} \mathrm{O}_{2}$.

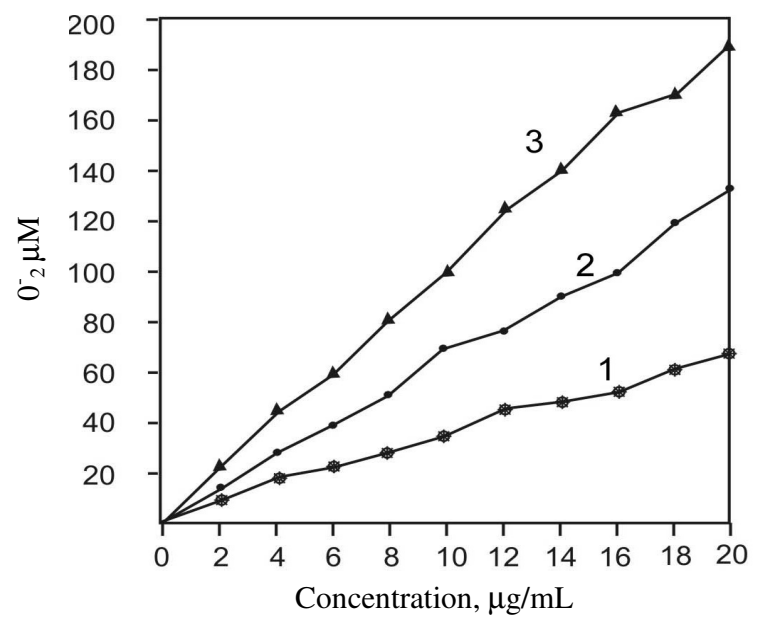

Figure 2. Relationship between the production of $0^{-2}$ and concentration $(0-20 \mu \mathrm{g} / \mathrm{mL})$ of the following: 1, metanil yellow; 2, p-ADPA: and 3, benzathrone.

Table 1. A comparison of chemical agents tested for ${ }^{1} \mathrm{O}_{2}$ and $\left(\mathrm{O}_{2}{ }^{-}\right)$production.

\begin{tabular}{ccc}
\hline Chemicals* & ${ }^{1} \mathrm{O}_{2}$ production & $\left(\mathrm{O}_{2}{ }^{-}\right)$production \\
\hline Benzanthrone & Mild & Mild \\
Metanil yellow & ND & Mild \\
$p$-ADPA & ND & Mild \\
\hline
\end{tabular}


The formation of ${ }^{1} \mathrm{O}_{2}$ by benzanthrone and $\left(\mathrm{O}_{2}{ }^{-}\right)$by metanil yellow, $p$-ADPA and benzanthrone might rise several question about their safety particularly in conjugation with exposure to sunlight. Studies shows that, exposure to metanil yellow, $p$-ADPA and benzanthrone may lead to various short and long term skin photosensitization and cell damaging effects.

Photosensitized reactions of dyes leading to the formation of activated oxygen species are believed to be a matter of great concern because the later are involved in the destruction of cells, tissues, phagocytes and certain cancer inducing processes ${ }^{5,7,9,11}$. Moreover, Bickers et $a l^{28}$ have demonstrated the destruction of epidermal cytochrome $P-450$ in epidermal microsomes by ${ }^{1} \mathrm{O}_{2}$ generated through photosensitization reactions induced by hematoporphyrin derivatives. Several other studies have also suggested that ${ }^{1} \mathrm{O}_{2},\left(\mathrm{O}_{2}{ }^{-}\right)$and other reactive forms of oxygen play a major role in the UV-induced membrane damaging reaction $^{29-30}$.

Although spectroscopic studies of cutaneous photosensitizing agent XVII benzanthrone were carried out by Reza Dabestani et $a l^{31}$. The important roles of reactive oxygen species in diseases related to aging and the necessity and benefits of antioxidative netraceuticals in prevention of disease and promotion of healthy aging reported in the recent years ${ }^{32-34}$.

\section{Conclusion}

Analysis was carried out of above dyes at concentration range of (1-10 $\mu \mathrm{g} / \mathrm{mL})$ and exposure period. At higher concentration the linearity was disturbed due to lack of penetration of solar radiation through the colloidal system.

\section{References}

1. Fernando A C, Kothari's Economic \& Industrial Guide of India, $34^{\text {th }}$ Ed., Chemicals \& Pharm., Kothari \& Sons, Madras, India. 1982/83, 6-7.

2. Munn A and Smagghe G, Encyclopaedia of Occupational Health and Safety (Parmeggiani, L., Ed.), International Labour Organization, Geneva III. Ed., 1, 1983, 699.

3. Joshi A, Khanna S K, Singh G B and Krishnamutri C R, Industrial Health, 1982, 20, 305-313.

4. Joshi A, Khanna S K, Singh G B and Krishnamutri C R, J Biosci., 1981, 3, 379-388.

5. Parrish J A, Anderson R R, Urbach F and Pitts D, UV-A, Biological Effects of Ultraviolet Radiations with Emphasis on Human Responses to Longwave Ultraviolet, Plenum Press, New York, 1978.

6. Prayer W A, Free Radicals in Biology, Academic Press, New York, 1976, 2, 85-133.

7. Krinsky N I, Singlet Oxygen (Wasserman H H and Murray R W, Eds.) Academic Press, New York, 1979, 597-667.

8. Joshi P C, Toxicol Lett., 1985, 26 ,211-217.

9. Marx J L, Science, 1983, 219, 158-159.

10. Trivedi D H and Niyogi A K, Indian J Indust Med., 1968, 14, 13.

11. Singh G B and Zaidi S H, J Ind Med Assoc., 1969, 52, 558-560.

12. Gurr E, Synthetic Dyes in Biology, Medicine and Industry, Academic Press, New York, 1971, 237.

13. Singh G B and Khanna S K, Indian J Exp Biol., 1979, 17, 1100-1102.

14. Srivastava L P, Khanna S K, Singh G B and Krishnamurti C R, Environ Res., 1982, 27, 185-189. 
15. Raza H, Biochemical Studies on Some Food Dyes, Ph.D. thesis submitted to Kanpur University, India, 1980.

16. Uniroyal Chemicals, $p$-Aminodiphenylamine, Naugatack (R) Chemicals, Division of Unioryal Inc, Naugatack C K, 1976.

17. Color Index, The Society of Dyers \& Colourists, England and The American Association of Textile Chemicals \& Colorists, U.S.A., 1971, 2, 2002.

18. Wall F E, Cosmetics Science and Technology (Balasam M S and Sagarin E, Eds.), Wiley, New York, 1972, 2, 306.

19. Szamarch H, Przeglad Dermatol., 1966, 53, 445-452.

20. Hatchard C G and Parker C A, Proc R Soc London, 1956, 235, 518-536.

21. Kraljic I and El Mohsni S, Photochem Photobiol., 1978, 28, 577-581.

22. Foote C S, Fugimoto T T and Chang Y C, Tetrahedron Lett., $1972, \mathbf{4 5 - 4 8 . ~}$

23. Quannes C and Wilson T J, Am Chem Soc., 1968, 90, 6527-6528.

24. Kearns D R, Singlet Oxygen (Wasserman H H and Murray R W, Eds.), Academics Press, New York, 1979, 115-137.

25. Korycka-Dahl M and Richardson T, J Dairy Sci., 1977, 61, 400-407.

26. McCord J M and Fridovich I, J Biol., 1969, 244, 4049-6055.

27. Joshi P C and Pathak M A, Biochem Biophys Res Commun., 1983, 112, 638-646.

28. Bickers D R, Dixit R and Mukhtar H, Biochem Biophys Res Commun., 1982, 108, 1032-1039.

29. Ito T, Photochem Photobiol., 1978, 28,493-508.

30. Anderson S M, Krinsky N I, Stone M R and Clagett D C, Photochem Photobiol., 1974, 20, 65-69.

31. Robert H Sik, Photochem Photobiol., 1992, 55(4), 533-539.

32. Galey J B, Int J Cosmet Sci., 1991, 13(2), 65-78.

33. Riley P A, Int J Radiat boil., 1994, 65(1), 27-33.

34. Lee J, Koo N and Min D B, Comprehensive reviews in food science and safety 2004, 3(1), 21-33. 


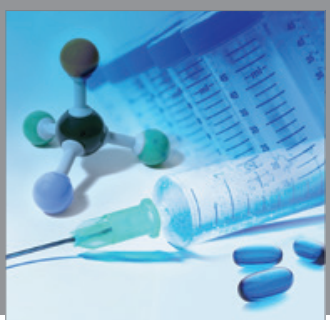

International Journal of

Medicinal Chemistry

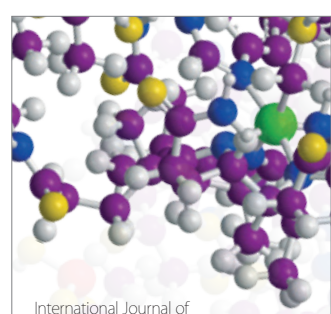

Carbohydrate Chemistry

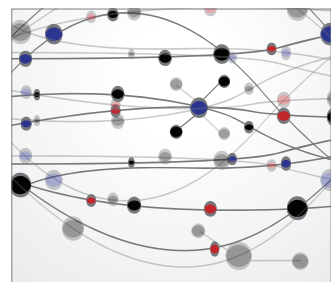

The Scientific World Journal
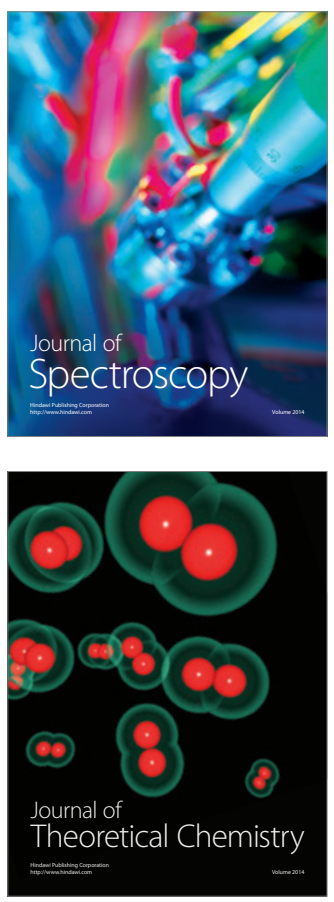
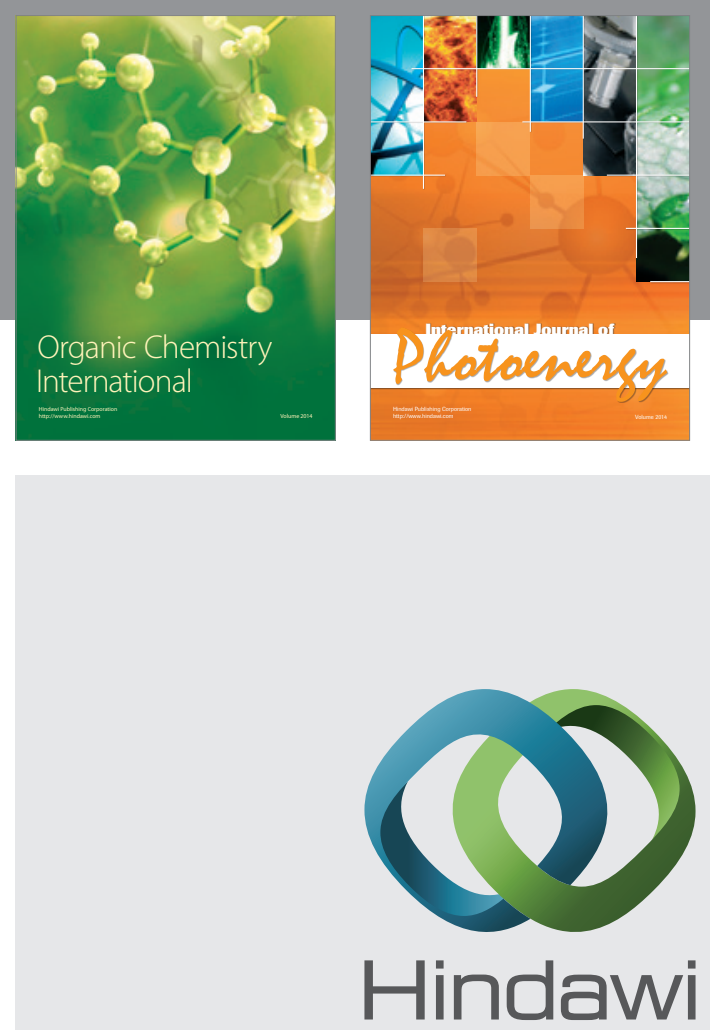

Submit your manuscripts at

http://www.hindawi.com
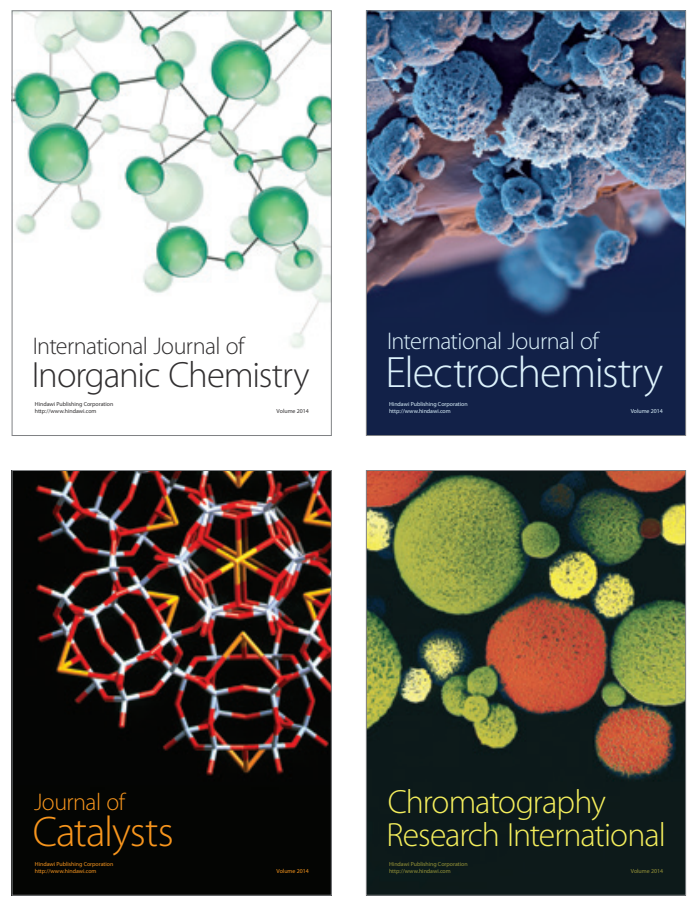
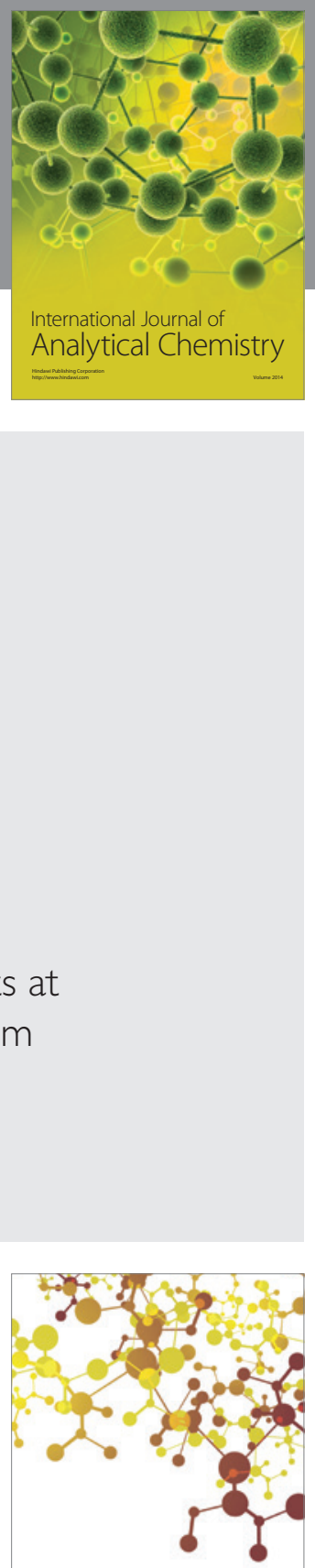

Journal of

Applied Chemistry
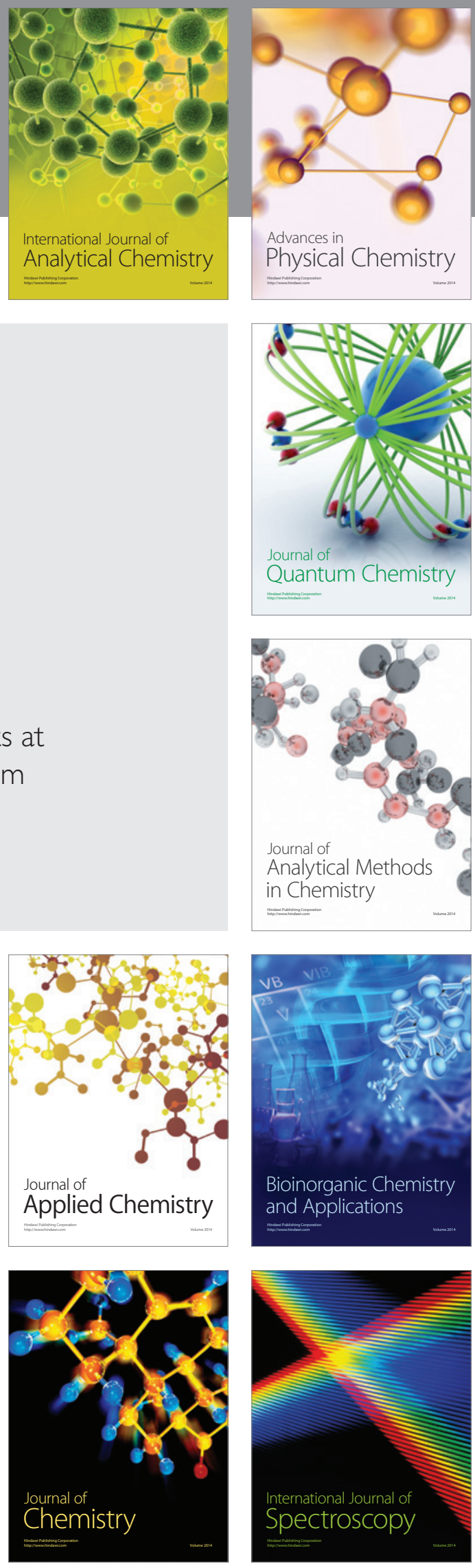